\title{
Differential effects of lead and zinc on inhibitory avoidance learning in mice
}

F.S. de O liveira,

M.R. Viana, A.R. Antoniolli and M. Marchioro
Departamento de Fisiologia, U niversidade Federal de Sergipe,
São Cristóvão, SE, Brasil

\section{Correspondence}

M. Marchioro

Departamento de Fisiologia

Universidade Federal de Sergipe

São Cristóvão, SE

Brasil

Fax: + 55-79-212-6660

E-mail: mmarchioro@uol.com.br

Research supported by CNPq

(PIBIC/UFS/CNPq) to F.S. de O liveira.

Received May 22, 2000

Accepted 0 ctober 31, 2000

\section{Abstract}

We studied the effects of chronic intoxication with the heavy metals lead $\left(\mathrm{Pb}^{2+}\right)$ and zinc $\left(\mathrm{Zn}^{2+}\right)$ on memory formation in mice. Animals were intoxicated through drinking water during the pre- and postnatal periods and then tested in the step-through inhibitory avoidance memory task. Chronic postnatal intoxication with $\mathrm{Pb}^{2+}$ did not change the step-through latency values recorded during the 4 weeks of the test (ANOVA, $\mathrm{P}>0.05$ ). In contrast, mice intoxicated during the prenatal period showed significantly reduced latency values when compared to the control group (day 1: $\mathrm{q}=4.62, \mathrm{P}<0.05$; day $7: \mathrm{q}=4.42, \mathrm{P}<0.05$; day $14: \mathrm{q}=5.65, \mathrm{P}<0.05$; day $21: \mathrm{q}=3.96, \mathrm{P}<0.05$, and day $28: \mathrm{q}=6.09$, $\mathrm{P}<0.05)$. Although chronic postnatal intoxication with $\mathrm{Zn}^{2+}$ did not alter a memory retention test performed $24 \mathrm{~h}$ after training, we noticed a gradual decrease in latency at subsequent 4-week intervals $(\mathrm{F}=3.07$, $\mathrm{P}<0.05$ ), an effect that was not observed in the control or in the $\mathrm{Pb}^{2+}$ treated groups. These results suggest an impairment of memory formation by $\mathrm{Pb}^{2+}$ when the animals are exposed during the critical period of neurogenesis, while $\mathrm{Zn}^{2+}$ appears to facilitate learning extinction.
Key words

- Lead

- Zinc

- Inhibitory avoidance

- Memory
The presence of high concentrations of heavy metals in the environment continues to be a matter of concern, especially with the increasing knowledge of their toxic effects, particularly on the central nervous system (CNS) of mammals (for a review, see Ref. 1).

Among the heavy metals which interact with the $\mathrm{CNS}, \mathrm{Pb}^{2+}$ is probably the most extensively studied, although the molecular targets and mechanisms of $\mathrm{Pb}^{2+}$ neurotoxicity have only recently been determined (1). Despite the lack of knowledge of a physiological function for $\mathrm{Pb}^{2+}$, the metal is known to have specific affinity for several $\mathrm{Ca}^{2+}$ binding sites in the brain, which regulate important functions such as neuronal matu- ration and synaptic plasticity (2). Several studies have demonstrated that $\mathrm{Pb}^{2+}$ impairs learning and memory processes both in animal models and in human beings $(3,4)$.

Zinc, on the other hand, is an endogenous metal which plays important roles in the modulation of some CNS functions. $\mathrm{Zn}^{2+}$ is found mainly in synaptic vesicles of the hippocampus, where it can be released together with glutamate, reaching concentrations as high as $300 \mu \mathrm{M}$ (5). Thus, $\mathrm{Zn}^{2+}$ can interact with either inhibitory (GABAergic) or excitatory (glutamatergic) neurotransmitter systems. When applied at high concentrations it has neurotoxic effects on neuron cultures (6), or, when present at concentrations be- 
low physiological values, it causes cognitive impairment (7). Moreover, $\mathrm{Zn}^{2+}$ has been implicated in the etiology of Alzheimer's disease, a pathological state which causes neurodegeneration in some brain areas with great impairment of cognition (8).

It has been well documented that longterm potentiation in the hippocampal formation plays an important role in learning and memory processes (9). When the brain is exposed to low doses of $\mathrm{Pb}^{2+}$, the metal appears to concentrate in this area (10). In this pathway, $\mathrm{Zn}^{2+}$ concentrations are higher (5), a fact that has led some of us to propose a possible interaction between these metals in the CNS (1).

Given the evidence for the differential actions of $\mathrm{Pb}^{2+}$ and $\mathrm{Zn}^{2+}$ on neuronal development and their concentrations in a brain area critical to memory formation, we evaluated the effects of chronic intoxication with these heavy metals during pre- and postnatal stages of development on performance in the step-through inhibitory avoidance task.

Forty-nine male and female Swiss mice (20-30 g) from our own colony were used. The animals were distributed into 4 experimental groups and maintained at constant temperature $\left(24.8 \pm 0.2^{\circ} \mathrm{C}\right)$, with free access to food and water. Mice were chronically intoxicated with lead acetate $(0.1 \%, \mathrm{w} / \mathrm{v})$ and zinc acetate $(1 \%, \mathrm{w} / \mathrm{v})$ through drinking water in two different developmental stages. For prenatal intoxication, a group of $5 \mathrm{fe}$ males were exposed to a solution of $0.1 \%$ $(w / v)$ lead acetate from the eleventh day of pregnancy (E11) to the fourth week after delivery (P28). The pups $(\mathrm{N}=15)$ were thus intoxicated during this period through maternal milk (prenatal lead group, PrePb) (11). For postnatal intoxication, a group of 13 mice were exposed to lead acetate at the same concentration for 60 days beginning during the second month of life (postnatal lead group, PostPb). Prenatal zinc intoxication was deleterious to the process of gestation and thus only animals exposed to a solution of $1 \%(\mathrm{w} / \mathrm{v})$ zinc acetate during the postnatal period (postnatal zinc group, PostZn; $N=9$ ) were studied. Exposure to $\mathrm{Zn}^{2+}$ was for 60 days beginning during the first month of life. The control group (Con) consisted of 12 mice which received tap water only. At the beginning of the experiment all mice were 3 months old.

The inhibitory avoidance (step-through) model was used to study the effects of lead and zinc on memory formation (12). Mice were trained in an inhibitory avoidance apparatus (FUNBEC, São Paulo, SP, Brazil) with two compartments ( $44 \times 15 \times 22 \mathrm{~cm})$, a light one and a dark one, separated by a sliding guillotine door. The lighted compartment was illuminated by a $60-\mathrm{W}$ lamp $20 \mathrm{~cm}$ above the floor, which consisted of a series of parallel 1-mm stainless steel bars spaced $0.5 \mathrm{~cm}$ apart. In the training session, mice were placed in the lighted chamber and the latency to enter the dark chamber was measured. When the animals entered the dark chamber with all four feet an electric shock (0.2 mA, 2-s duration) was applied to their paws with a 611 stimulator (Phipps \& Bird, Richmond, VA, USA) and they were immediately returned to the home cage. The memory retention test was performed $24 \mathrm{~h}$ later by repeating the same protocol, except that now the shock was omitted. The differences between the training and testing latencies were used as parameters for memory acquisition. To determine the rate of extinction, we repeated the retention test on the 7th, 14th, 21st and 28th days.

There was no difference in latency to first entry into the dark chamber between the 4 experimental groups (day $0: \mathrm{F}=0.93, \mathrm{P}>0.4$, one-way ANOVA), indicating that chronic intoxication with $\mathrm{Pb}^{2+}$ and $\mathrm{Zn}^{2+}$ did not interfere with the exploratory behavior of the animals. Repeated measures ANOVA for each group revealed significant differences in these values between the training (day 0) and testing days (days 1 to 28 ) (Con: $\mathrm{F}=$ 9.40, $\mathrm{P}<0.01 ; \mathrm{PrePb}: \mathrm{F}=2.98, \mathrm{P}<0.05$; 
PostPb: $\mathrm{F}=5.25, \mathrm{P}<0.01$, and PostZn: $\mathrm{F}=$ 5.31, $\mathrm{P}<0.01$ ), showing that mice learned to avoid the dark chamber after receiving an electric shock.

Significant differences were found in retention scores among the 4 groups and days tested (Table 1) (day 1: $\mathrm{F}=4.55, \mathrm{P}<0.01$; day $7: \mathrm{F}=3.45, \mathrm{P}<0.05 ;$ day $14: \mathrm{F}=4.80, \mathrm{P}<0.01$; day 21: $\mathrm{F}=2.81, \mathrm{P}<0.05$, and day $28: \mathrm{F}=$ 6.73, $\mathrm{P}<0.01)$. The latencies for the PrePb group during days 1 to 28 were lower than those for the Con group (Tukey multiple comparison test for day $1: \mathrm{q}=4.62, \mathrm{P}<0.05$; day $7: \mathrm{q}=4.42, \mathrm{P}<0.05$; day $14: \mathrm{q}=5.65$, $\mathrm{P}<0.05$; day $21: \mathrm{q}=3.96, \mathrm{P}<0.05$, and day $28: \mathrm{q}=6.09, \mathrm{P}<0.05)$. The same was not true when the latencies for the Con group were compared to those for the PostPb (day $1: \mathrm{q}=$ 2.19 , NS; day $7: \mathrm{q}=2.59$, NS; day $14: \mathrm{q}=$ 1.89 , NS; day $21: \mathrm{q}=2.37$, NS, and day 28 : $\mathrm{q}=3.40, \mathrm{NS}$ ) and PostZn groups (day $1: \mathrm{q}=$ 0.005 , NS; day $7: \mathrm{q}=1.12$, NS; day $14: \mathrm{q}=$ $1.89, \mathrm{NS}$; day $21: \mathrm{q}=2.37, \mathrm{NS}$, and day 28 : $q=3.40, N S$ ). These results suggest that only intoxication with $\mathrm{Pb}^{2+}$ during the prenatal period affected memory retention.

Finally, to study the learning extinction pattern, we separately evaluated the latencies for each group and test session. Repeated measures ANOVA showed no differences among those of the Con $(F=0.37$, $\mathrm{P}>0.5), \operatorname{PrePb}(\mathrm{F}=1.78, \mathrm{P}>0.14)$ and PostPb $(\mathrm{F}=0.29, \mathrm{P}>0.87)$ groups. In contrast, for the PostZn group there were significant differences $(\mathrm{F}=3.13, \mathrm{P}<0.05)$. The post hoc Tukey multiple comparison test showed that the latencies recorded on day $28(\mathrm{P}<0.05)$ were lower when compared to the first testing day for this group (Table 1), suggesting an effect of $\mathrm{Zn}^{2+}$ on the mechanism of learning extinction.

The results showed an impairment of memory formation by $\mathrm{Pb}^{2+}$ when exposure occurred during the prenatal phase, while $\mathrm{Zn}^{2+}$ accelerated learning extinction. $\mathrm{Pb}^{2+}$ exposure during the postnatal phase did not affect latency values, supporting the view that the mature brain is insensitive to the deleterious effects of this heavy metal. In addition, data from our laboratory (de Oliveira FS and Marchioro M, unpublished results) have shown that acute $\mathrm{Pb}^{2+}$ administration (ip, up to $500 \mathrm{mg} / \mathrm{kg}$ ) has no effect on step-through inhibitory avoidance acquisition and consolidation. However, we noticed a significant impairment of memory in animals whose mothers had been exposed to $\mathrm{Pb}^{2+}$ during the gestational period, which impairment may have been related to a possible inhibitory action of $\mathrm{Pb}^{2+}$ on immature hippocampal neurons. $\mathrm{Pb}^{2+}$, by interfering with synapse formation, may compromise in an irreversible manner the mechanisms responsible for inhibitory avoidance memory formation.

Chronic $\mathrm{Zn}^{2+}$ administration during the

Table 1 - Latency to enter the dark chamber (mean \pm SEM) for the control group (Con), prenatal lead group (PrePb), postnatal lead group (PostPb) and postnatal zinc group (PostZn).

$++\mathrm{P}<0.01$ compared to the subsequent sessions (repeated measures ANOVA); $* \mathrm{P}<0.05$ compared to the respective control group (Tukey multiple comparison test after one-way ANOVA); ${ }^{+P}<0.05$ compared to the first testing day (Tukey multiple comparison test after repeated measures ANOVA).

\begin{tabular}{ccccc}
\hline Days & Con & PrePb & PostPb & PostZn \\
\hline 0 & $21.58 \pm 4.33^{++}$ & $22.13 \pm 4.64^{++}$ & $16.61 \pm 4.04^{++}$ & $29.11 \pm 7.37^{++}$ \\
1 & $246.83 \pm 28.74$ & $120.60 \pm 28.90^{*}$ & $186.53 \pm 29.17$ & $246.66 \pm 24.59$ \\
7 & $242.00 \pm 26.75$ & $111.73 \pm 28.23^{*}$ & $163.15 \pm 34.24$ & $204.22 \pm 41.02$ \\
14 & $243.11 \pm 35.36$ & $83.80 \pm 24.32^{*}$ & $191.00 \pm 31.68$ & $182.44 \pm 47.31$ \\
21 & $224.83 \pm 35.50$ & $104.66 \pm 27.16^{*}$ & $180.30 \pm 30.70$ & $142.44 \pm 34.95$ \\
28 & $201.33 \pm 32.76$ & $35.13 \pm 17.25^{*}$ & $154.33 \pm 34.85$ & $95.44 \pm 34.55^{+}$
\end{tabular}


postnatal period did not interfere with memory formation. Nevertheless, we observed a gradual decrease of the latency values throughout the 4 weeks tested, indicating facilitation of learning extinction or forgetting the habit.

Several recent studies have proposed the hippocampal formation to be the main target for the actions of $\mathrm{Pb}^{2+}$ and $\mathrm{Zn}^{2+}$, although to date no direct evidence has been presented. Assaf and Chung (5) demonstrated that $\mathrm{Zn}^{2+}$ is released together with glutamate from hippocampal neurons. Accordingly, $\mathrm{Pb}^{2+}$ also preferentially accumulates in this brain area (13). A direct way to determine the cellular targets of $\mathrm{Pb}^{2+}$ and $\mathrm{Zn}^{2+}$ would be the use of stereotaxic microinjections of these metals into different areas of the hippocampus (14). These experiments are currently being performed in our laboratory.

Our results show differential effects for the heavy metals $\mathrm{Pb}^{2+}$ and $\mathrm{Zn}^{2+}$ on inhibitory avoidance learning in mice. The effects seem to be related to the first phases of neuronal development and synaptogenesis.

\section{Acknowledgments}

The authors wish to thank Dr. Celso Morato, Department of Biology, Universidade Federal de Sergipe, for a critical discussion of the results presented in this report.

\section{References}

1. Swanson $\mathrm{KL}$, Marchioro $M$, Ishihara $K$, Alkondon M \& Albuquerque EX (1996). Neuronal targets of lead in the hippocampus: Relationship to low level lead intoxication. Comprehensive Toxicology, 11: 470-491.

2. Goldstein GW (1993). Evidence that lead acts as a calcium substitute in second messenger metabolism. Neurotoxicology, 14: 97-102.

3. Bellinger D \& Dietrich KN (1994). Low lead exposure and cognitive function in children. Pediatric Annals, 23: 600-605.

4. McMichael AJ, Baghurst PA, Wigg NR, Vimpani GV, Robertson EF \& Roberts RJ (1988). Port Pirie cohort study: Environmental exposure to lead and children's ability at the age of four years. New England J ournal of Medicine, 319: 468-475.

5. Assaf SY \& Chung SH (1984). Release of endogenous zinc from brain tissue during activity. Nature, 308: 734-736.

6. Manev H, Kharlamov E, UzT, Manson P \&
Cagnoli CM (1997). Characterization of zinc-induced neuronal death in primary cultures of rat cerebellar granule cells. Experimental Neurology, 146: 171-178.

7. Petit TL \& LeBoutillier JC (1986). Zinc deficiency in the postnatal rat: implications for lead toxicity. Neurotoxicology, 7: 237-246.

8. Arapsi N, Pollard HB \& Rojas E (1996). $\mathrm{Zn}^{2+}$ interaction with Alzheimer amyloid beta protein calcium channels. Proceedings of the National Academy of Sciences, USA, 93: 1710-1715.

9. Izquierdo I \& Medina J H (1995). Correlation between the pharmacology of longterm potentiation and the pharmacology of memory. Neurobiology of Learning and Memory, 63: 19-32.

10. Collins MF, Herdina PD, White $E \&$ Singhal $\mathrm{RL}$ (1982). Lead in blood and brain regions of rats chronically exposed to low doses of the metal. Toxicology and Applied Pharmacology, 65: 314-322.
11. Cory-Slechta D (1995). MK-801 subsensitivity following postweaning lead exposure. Neurotoxicology, 16: 83-95.

12. Lorenzini CGA, Baldi $E$, Bucherelli $C$, Sacchetti B \& Tassoni G (1998). Temporal characterization of subcortical nuclei in mnemonic processes: Results of tetrodotoxin reversible inactivation studies in the rat. Archives Italiennes de Biologie, 136: 279-296.

13. Fjerdingstad EJ, Danscher G \& Fjerdingstad E (1974). Hippocampus: Selective concentration of lead in the normal rat brain. Brain Research, 80: 350-354.

14. Fregoneze J B, Luz CP, Sarmento C, Gonzalez V, Oliveira P, Santana J $r$ P, Marinho CA, Castro L, Nascimento T, De Paula S, Lima AKS, De Oliveira IR \& De Castro-e-Silva E (1998). Central lead administration induces natriuretic and kaliuretic effects in rats. Physiology and Behavior, 65: 321-326. 